L.-L. YANG, D. EVANS, B. XU, W.-T. LI, M.-L. LI, S.-F. ZHU*, K. N. HOUK*, Q.-L. ZHOU* (NANKAI UNIVERSITY, TIANJIN, P. R. OF CHINA AND UNIVERSITY OF CALIFORNIA, LOS ANGELES, USA )

Enantioselective Diarylcarbene Insertion into Si-H Bonds Induced by Electronic Properties of the Carbenes J. Am. Chem. Soc. 2020, 142, 12394-12399.

\section{Rhodium-Catalyzed Enantioselective Diarylcarbene Insertion into Si-H Bonds}<smiles>[R][R]1ccc(C(=N)c2ccc([R3])cc2)cc1</smiles>

(1.2 equiv)<smiles>[R7]c1ccc(C([AsH3])c2ccc([Tl])cc2)cc1</smiles>

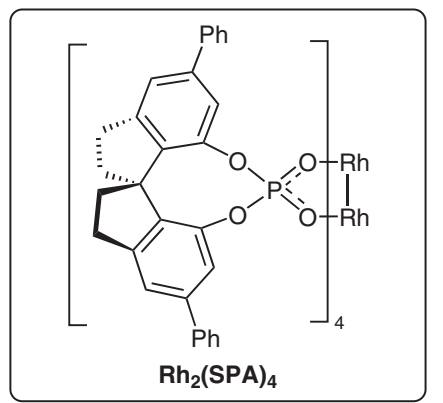

\section{Category}

Metals in Synthesis

\section{Key words}

asymmetric catalysis

carbenes

rhodium catalysis

silanes

\section{Synfact 3 of the Month}

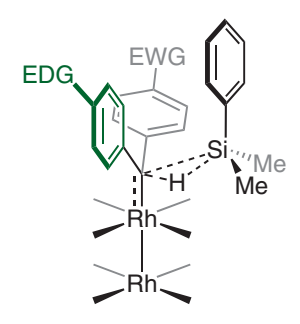

Model for selectivity:

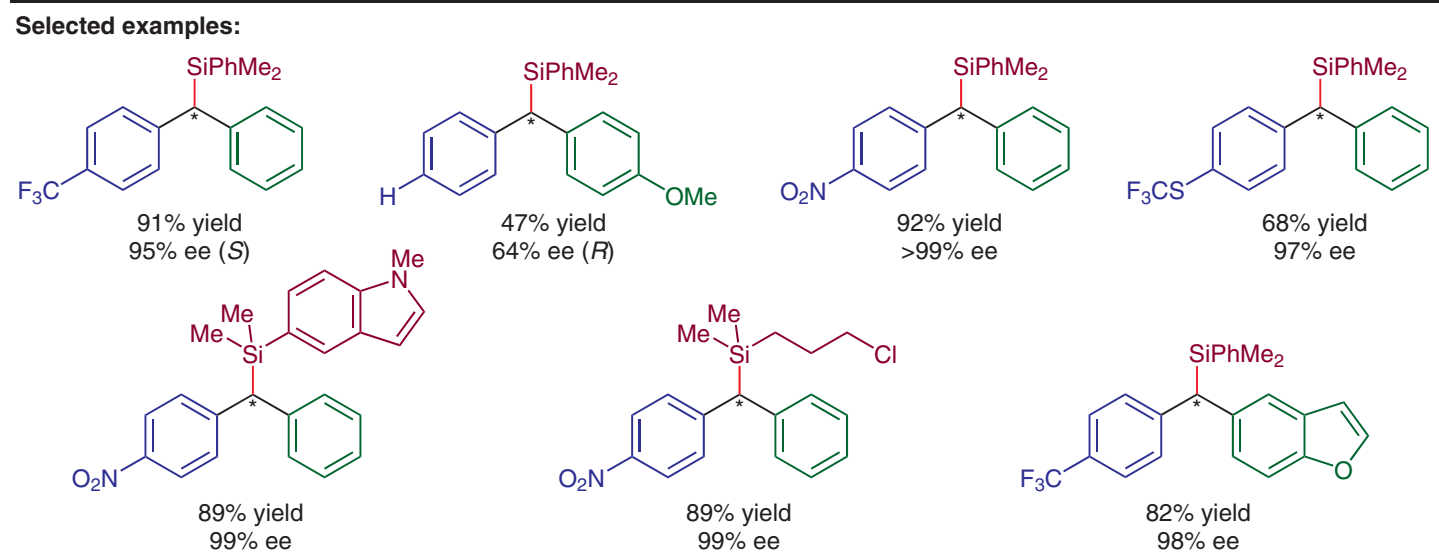

Significance: The authors describe a rhodiumcatalyzed asymmetric coupling of silanes with diaryldiazomethanes. The enantioselection is shown to be induced by the electronic properties of the aryl substituents of the carbene rather than sterics.
Comment: DFT studies support the conclusion that, in the favored transition state, the more electron-rich aryl group is coplanar with the carbene empty p-orbital while the other ring is orthogonal, resulting in their differentiation. 